\title{
GIANT CELL TUMOR OF THE THORACAL SPINE: CASE REPORT
}

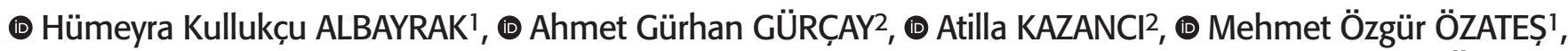 \\ (1) Oktay GÜRCAN ${ }^{1}$
}

\author{
${ }^{1}$ Ankara City Hospital, Clinic of Neurosurgery, Ankara, Turkey \\ ${ }^{2}$ Yıldırım Beyazıt University Faculty of Medicine, Department of Neurosurgery, Ankara, Turkey
}

\begin{abstract}
Giant cell tumor is one of the benign tumors of bone that typically originate from the meta-epiphysial ends of long bones. It constitutes approximately $5 \%$ to $10 \%$ of all bone tumors in adults. These rarely seen tumors in the spine often present with nonspecific localized pain due to bone involvement. Diagnosis is made by demonstrating osteolytic bone lesion by direct X-ray and computed tomography. Surgical excision, radiotherapy and immunotherapy are the main treatment modalities. Herein we report a young female patient presented to our clinic with back pain and hypoesthesia in her legs. Lytic bone lesion in the second thoracic vertebra was radiologically demonstrated. After subtotal excision, histopathological examination revealed giant cell tumor of the bone. Diagnosis and treatment approaches in our case were discussed by reviewing the literature.
\end{abstract}

Keywords: Giant cell tumor, primary bone tumor, thoracic spine

\section{INTRODUCTION}

Giant cell tumor (GCT) is one of the benign tumors of bone that typically originate from the meta-epiphysial ends of long bones such as the distal femur, proximal tibia, and distal radius $^{(1)}$. Generally, it is seen slightly more in women who have completed skeletal maturation in the third and fourth decades(2). GCT is rarely seen in the spine. Spine location is mostly in the spine body rather than in the posterior elements(3). In contrast to GCT seen in the extremities, those with spine localization are seen in younger patients ${ }^{(4)}$. In this case report, a 28-year-old female patient who was operated on and diagnosed as GCT was discussed by reviewing the literature.

\section{CASE REPORT}

A 28-year-old female patient was admitted to our clinic with the complaints of back pain localized to upper thoracic spine and hypoesthesia in the legs. These complaints had been present for 1 year and increased in the last 3 months. She had a diagnosis of lumbar discopathy and underwent various medical/physical therapies. However, her complaints increased and thoracal magnetic resonance imaging (MRI) revealed a mass lesion in the thoracic two vertebra on contrast-enhanced series. On admission, the right extensor hallucus longus and foot dorsal flexion was at 4/5 strength, and under T5 level, there was hypoesthesia. Also, there was bilateral Babinski pathological reflex and impaired tandem gait. Thoracic computed tomography (CT) and MRI showed a lytic lesion in the thoracic two vertebral corpus extending to the surrounding tissue (Figures 1-2). With the diagnosis of T2 vertebrae mass, patient underwent operation. Subtotal excision was performed macroscopically with malignant tumor bone excision after C7-T4 posterior instrumentation via posterior approach. Arthrodesis was achieved by T2 corpectomy + cage fusion implementation (Figure 3). As a result of histopathological examination, due to the presence of a plurality of multinuclear giant cells between oval round nuclei, open chromatinous, nucleolated mononuclear cells and foamy histiocytes in some

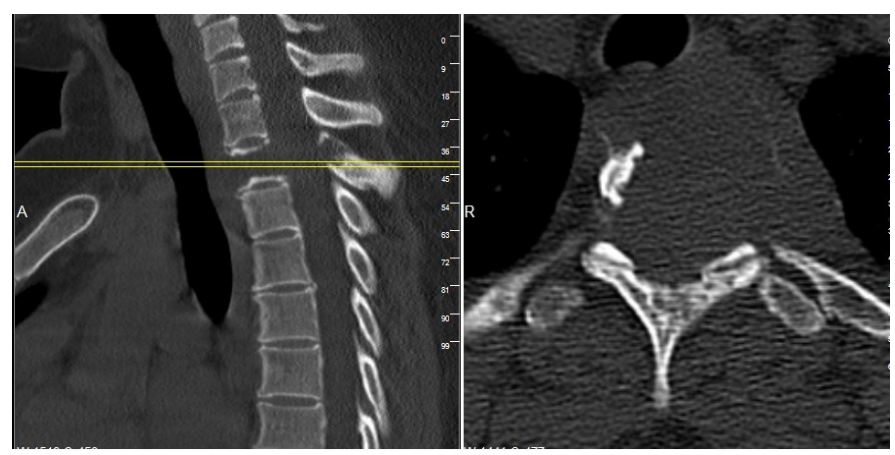

Figure 1. Preoperative $\mathrm{CT}$ results $\mathrm{CT}$ : Computed tomography 
turkishspine

areas, occasional bleeding areas, hemosiderin pigment and bone spicules, and also the presence of reactive osteoid formation as small foci within the tumor, the tumor was evaluated as a giant cell tumor of bone in the intermediate group (Figure 4). Postoperative thoracic CT and MRI examinations revealed subtotal excision of the tumor. The patient was discharged with a thoracic corset on the $7^{\text {th }}$ postoperative day without any additional deficit. Denosumab/Filgrastim + Lenogastrim

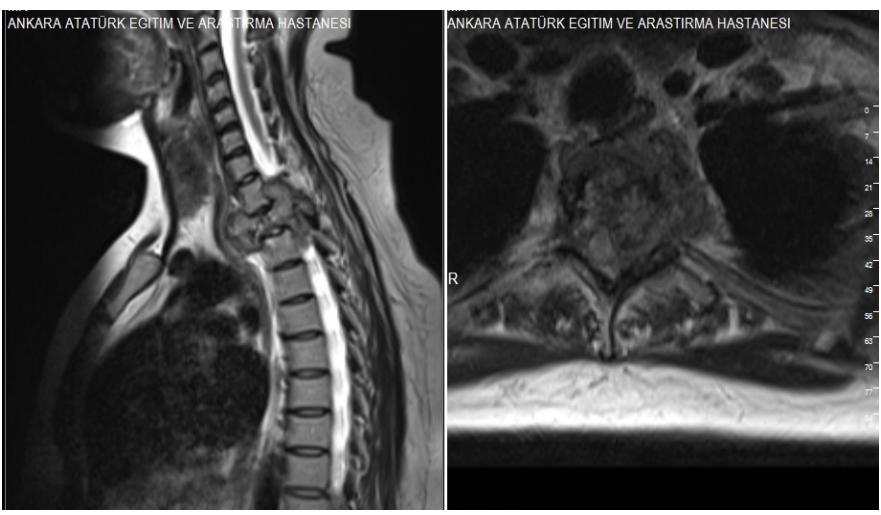

Figure 2. Preoperative MR results

MR: Magnetic resonance

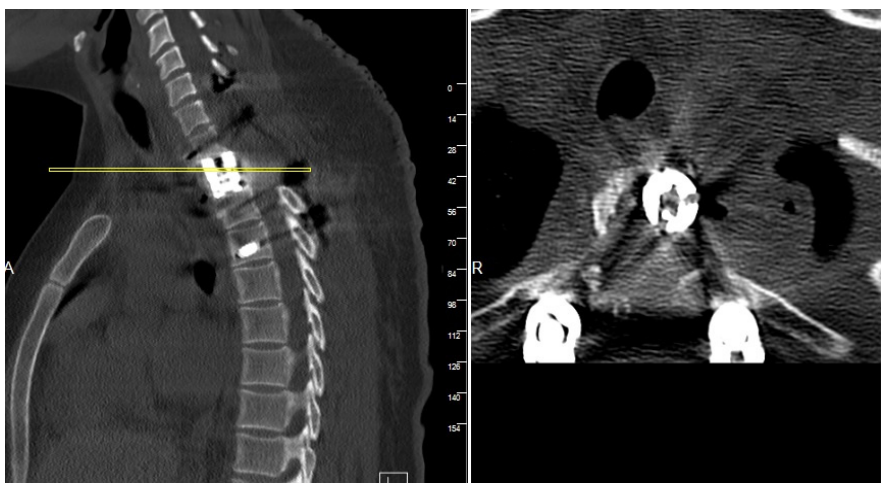

Figure 3. Postoperative $1^{\text {st }}$ day $\mathrm{CT}$ results

$\mathrm{CT}$ : Computed tomography

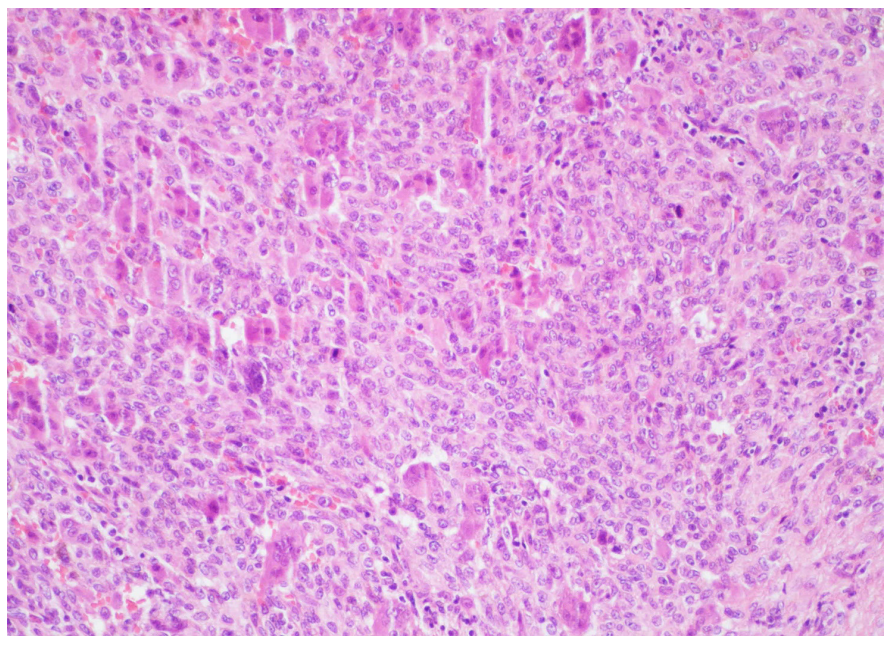

Figure 4. Patology results treatment was started after the patient was evaluated by the oncology department after discharge. There is no regression or progression for the residual mass, it is stable. There is no new lesion in the 4-year follow-up (Figure 5,6).

\section{DISCUSSION}

GCT is one of the benign tumors of bone, which usually originates from the metaepiphysial ends of long bones and constitutes approximately $5 \%$ to $10 \%$ of all bone tumors in adults $^{(1)}$. It is mostly seen in females who have completed skeletal maturation in the third and fourth decades of life(2). Spine location is mostly in the spine body rather than the posterior elements. GCT is generally located in corpus against the posterior elements in the spine ${ }^{(3)}$. In our 28-year-old female case, the mass was located in the thoracic two vertebra corpus in accordance with the literature.

Patients commonly present with back pain. Since the first symptom is usually back pain, it may cause misinterpretations and delay in diagnosis ${ }^{(2,3)}$. With the growth of tumor size, localized pain may present with swelling and compression of spinal cord or nerve roots on the affected side and present with neurological deficits ${ }^{(5,6)}$. Similarly, our patient received medical and physical therapy with the complaint of back pain and with
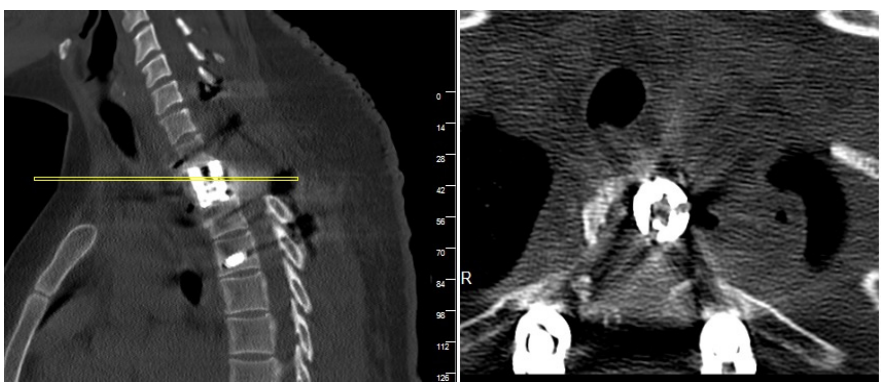

Figure 5. Postoperative $4^{\text {th }}$ year CT CT: Computed tomography

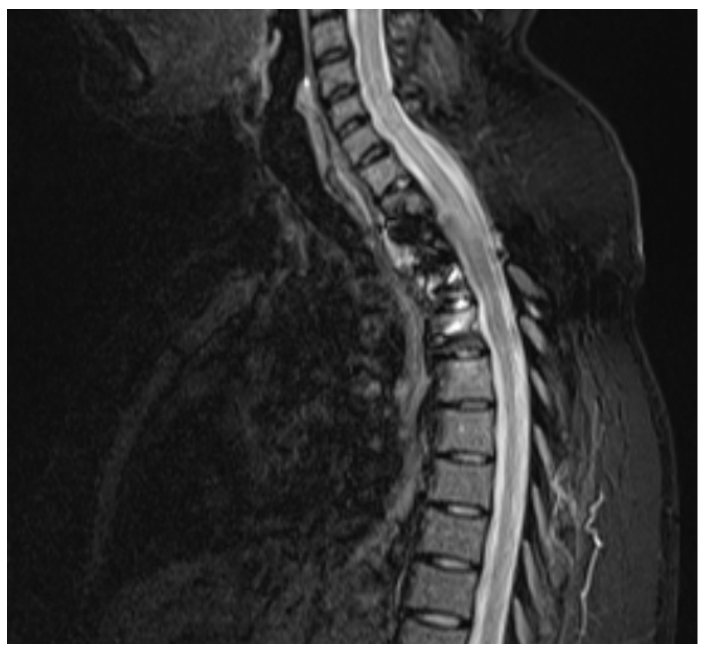

Figure 6. Postoperative $4^{\text {th }}$ year MR MR: Magnetic resonance 
the diagnosis of lumbar disc disease for about 1 year in various centers. After weakness of the lower extremity and sensory deficits, the patient was diagnosed with thoracic mass.

The most common localization of GCT in the spine is the sacrum and these localized tumors are diagnosed late due to nonspecific symptoms and show a more aggressive course $\mathrm{e}^{(7)}$. Depending on the location of the tumor in the sacrum, they may present with weakness in the gastrocnemius muscle in the upper sacral location, loss of bladder and bowel control in the lower sacral location, and perineal numbness and sexual dysfunction ${ }^{(8)}$. In our case, thoracic spine involvement, which is a rare localization, was present.

It is usually seen as a destructive, osteolytic lesion in radiologic imaging. Generally, they can be distinguished from other bone tumors by their radiological appearance. In our patient, as seen on thoracic $\mathrm{CT}$, there was a well-circumscribed lytic lesion in the T2 vertebra corpus (Figure 1). CT and MRI provide detailed information about bone involvement, surrounding soft tissue and bone marrow ${ }^{(3)}$; bleeding, cysts and necrosis areas may vary due to variable signal intensities. Similarly, in our case, MRI of the tumor showed heterogeneous iso- or hypointense on T1-weighted sequences and heterogeneous hyperintense on T2-weighted sequences (Figure 2). It should be noted that GCT can occur in two separate vertebrae. For this purpose, the whole spine should be investigated preoperatively by bone scintigraphy or $\mathrm{CT}^{(9)}$. In our case, preoperative scintigraphy and spinal CT were performed and no second focus was detected. The treatment of GCT is more complex due to limited surgical access to the spine, differences in vascular structures, and proximity to the spinal cord and nerve roots, as opposed to tumors in other regions. Radical excision of GCT is accepted as the best treatment option ${ }^{(10)}$. Although lower margin recurrence rates are seen in wide marginal resection or en-bloc resection of the tumor, this can often lead to serious neurological impairment ${ }^{(11)}$. Neoadjuvant treatments (neoadjuvant chemotherapy, selective arterial embolization) can be used before the surgery. Selective arterial embolization (SEE) reduces the amount of intraoperative bleeding when applied 24 hours before the surgery. There are also studies reporting a reduction in recurrence rates. SEE may act as a neoadjuvant therapy rather than a stand-alone treatment, as it alone does not provide local control. Chemotherapeutic agents are used in preoperative (Neo-adjuvant Immunotherapy) and postoperative (Adjuvant Immunotherapy) treatments. As Bisphosphonates and Denosumab are involved in the apoptosis of tumor cells and they inhibit the growth of GCT cells by inhibiting osteoclast differentiation, the use of these drugs before and after surgery is recommended ${ }^{(12,13)}$. The dimensions of surgical excision and adjuvant treatments [Radiotheraphy (RT) and immunotherapy] depend on many factors such as tumor location and patient comorbidity. Whether RT is given is controversial. The efficacy of RT and the frequency of sarcomatous conversion are two major concerns about the frequency of this therapy. RT may be an alternative treatment in cases where complete excision is not possible or there is excessive morbidity. Other adjuvant therapies such as freezing, argon beam coagulation, radioactive particles and cementation may be useful, but there is no clear study of these methods. In our case, Denosumab/Filgrastim + Lenogastrim treatment was initiated by Oncology Department after discharge. RT was not applied because of the possibility of sarcomatous transformation.

Although GCT is generally accepted as benign, they may display malignant aggressive behavior such as local invasion and lung metastasis less frequently ${ }^{(14)}$. Since these tumors have local aggressive ability, local recurrence rate is quite high if adequate excision is not performed ${ }^{(10)}$. The local recurrence rate varies between $10 \%$ and $40 \%$ depending on surgical intervention and treatment ${ }^{(15)}$. The recurrence rate is higher in patients under 30 years of age ${ }^{(16)}$. Thorax CT was performed in our patient for possible preoperative lung metastasis exclusion and no signs of metastasis were detected. There was no recurrence in the 4-year follow-up of our patient who underwent total excision and immunotherapy after surgery (Figures 5,6).

\section{CONCLUSION}

The giant cell tumor of the bone, which presents with nonspecific back and low back pain and rarely with spine involvement in long bones especially in middle-aged women, should be considered in the differential diagnosis. Although it is generally accepted as benign, the combination of neoadjuvant treatments (SEE, Immunotherapy), radical excision and postoperative relapse reduction (RT, Bisphosphonates, Denosumab) is the most appropriate treatment because of high local recurrence rates after inadequate surgery.

\section{Ethics}

Informed Consent: Informed consent form was obtained from the patients.

\section{Authorship Contributions}

Concept: H.K.A., A.G.G., O.G., Design: H.K.A., A.K., M.Ö.Ö., Data Collection or Processing:H.K.A.,Analysis or Interpretation:H.K.A., A.G.G., O.G., A.K., Literature Search: H.K.A., O.G., A.K., M.Ö.Ö., Writing: H.K.A., A.K., O.G.

Conflict of Interest: No conflict of interest was declared by the authors.

Financial Disclosure: The authors declared that this study received no financial support.

\section{REFERENCES}

1. Larsson SE, Lorentzon R, Boquist L. Giant-cell tumor of bone. A demographic, clinical and histopathological study of all cases recorded in the Swedish Cancer Registry fort he years 1958 through 1968. J Bone Joint Surg Am. 1975;57:167-73.

2. Balke M, Henrichs MP, Gosheger $G$, Ahrens $H$, Streitbuerger $A$, Koehler $\mathrm{M}$, et al. Giant cell tumors of the axial skeleton. Sarcoma. 2012;410973.

3. Kim HM, Lee JE, Jung SS, Chon J, Yoon DH, Park YK, et al. Spinal Cord Injury due to the Giant Cell Tumor of the second Thoracic Vertebra: A case Report. Ann Rehabil Med. 2013;37:269-73. 
turkishspine

4. Dahlin DC. Giant-cell tumor of vertebrae above the sacrum: a review of 31 cases. Cancer. 1977;39:1350-6.

5. Kumar R, Guinto FC, Madewell JE, David R, Shirkhoda A. Expansile bone lesions of the vertebra. Radiographics. 1998;8:749-69.

6. Sanjay BK, Frassica FJ, Frassica DA, Unni KK, Mcleod RA, Sim FH. Treatment of gaint-cell tumor of the pelvis. J Bone Joint Surg Am. 1993;75:1466-75.

7. Althausen PL, Schneider PD, Bold RJ, Gupta MC, Goodnight JE, Khatri VP. Multimodality management of a giant cell tumor arising in the proximal sacrum: case report. Spine (Phila Pa 1976). 2002;27:E361-5.

8. Dahlin DC. Caldwell Lecture. Giant cell tumor of bone: highlights of 407 cases. AJR Am J Roentgenol. 1985;144:955-60.

9. Kos CB, Taconis WK, Fidler MW, ten Velden JJ. Muitifocal giant cell tumors in the spine. A case report. Spine (Phila Pa 1976). 1997;22:821-2.

10. Junming $M$, Cheng $Y$, Dong $C$, Jianru $X$, Xinghai $Y$, Quan $H$, et al. Giant cell tumor of the servical spine: a series of 22 cases and outcomes. Spine (Phila Pa 1976). 2008;33:280-8.
11. Martin C, McCarthy EF. Giant cell tumor of the sacrum and spine: series of 23 cases and a review of the literatüre. lowa Orthop J. 2010;30:69-75.

12. Cheng YY, Huang L, Lee KM, Xu JK, Zheng MH, Kumta SM. Bisphosphonates induce apoptosis of stromal tumor cells in giant cell tumor of bone. Calcif Tissue Int. 2004;75:71-7.

13. Li G, Fu D, Chen K, Ma X, Sun M, Sun W, et al. Surgical strategy fort he management of sacral giant cell tumors: a 32-case series. Spine J. 2012;12:484-91.

14. Lausten GS, Jensen PK, Schiodt T, Lund B. Local recurrences in giant cell tumor of bone. Longterm follow up of 31 cases. Int Orthop. 1996;20:172-6.

15. Kathiresan AS, Johnson JN, Hood BJ, Montoya SP, Vanni S, GonzalezQuintero VH. Giant cell bone tumor of the thoracic spine presenting in late pregnancy. Obstet Gynecol. 2011;118:428-31.

16. Bertoni F, Present D, Enneking WF. Giant-cell tumor of bone with pulmonary metastases. J Bone Joint Surg Am. 1985;67:890-900. 